\title{
INTERSEÇÕES ENTRE ENSINO, FORMAÇÃO HUMANÍSTICA E PROJETO DE EXTENSÃO A PARTIR DE UMA EXPERIENCIA PRÁTICA COM FOTOGRAFIA
}

\author{
José Duarte Barbosa Júnior; Cristiane De Brito Cruz \\ duarte.junior@ifrn.edu.br; cristiane.cruz@ifrn.edu.br \\ Instituto Federal de Educação, Ciência e Tecnologia do Rio Grande do Norte \\ DOI: $10.15628 /$ rbept.2018.6877
}

Artigo submetido em dez/2017 e aceito em fev/2018

\section{RESUMO}

O presente trabalho aborda os resultados do projeto de extensão "Revelando histórias do Seridó Negro" e sua contribuição para seus participantes e para a formação dos estudantes e docentes envolvidos. 0 projeto buscou, inicialmente, conhecer histórias das populações negras da região Seridó do Rio Grande do Norte - Brasil, especificamente na comunidade da Boa Vista, município de Parelhas/RN. Através de metodologias da imagem e da voz que retratam a vida cotidiana, buscou dar visibilidade à cultura negra seridoense para materializala em uma exposição fotográfica. Constata-se, com a experiência, a importância de atividades dessa natureza, na potencialização de habilidades e no desenvolvimento de novas percepções sobre a realidade local. Nota-se uma interseção entre o ensino da sociologia/antropologia no currículo das estudantes bolsistas e a formação humanística delas, ou seja, uma articulação de saberes que foram socializados via projeto. Percebe-se, por fim, a importância do projeto de extensão como espaço de produção de vínculos com as comunidades e de socialização do conhecimento.

PALAVRAS-CHAVE: Projeto de extensão, ensino, comunidades quilombolas, fotografia. 


\section{INTERSECTIONS BETWEEN TEACHING, HUMANISTIC EDUCATION AND PROJECT EXTENSION FROM A PRACTICAL EXPERIENCE WITH PHOTOGRAPHY}

José Duarte Barbosa Júnior; Cristiane De Brito Cruz duarte.junior@ifrn.edu.br; cristiane.cruz@ifrn.edu.br Instituto Federal de Educação, Ciência e Tecnologia do Rio Grande do Norte

DOI: $10.15628 /$ rbept.2018.6877

Artigo submetido em dez/2017 e aceito em fev/2018

\section{ABSTRACT}

This paper deals with the results of the extension project "Revelando histórias do Seridó Negro" ("Developing histories from Black Seridó") and its contribution to the participants and to education of students and teachers involved. The project initially sought to know the stories of black populations in the Seridó region of Rio Grande do Norte - Brazil, specifically in the community of Boa Vista, Parelhas/RN. Through methodologies of the image and the voice that show the daily life, it sought to give visibility to the Seridó black culture to organize it in a photographic exhibition. The experience shows the importance of activities of this nature, the potentialization of skills and the development of new perceptions about the local reality. There is an intersection between the teaching of sociology/anthropology in the curriculum of scholarship students and their humanistic formation, that is, an articulation of knowledges that were socialized bya the project. Finally, we see the importance of the university extension project as a space for the production of links with communities and the socialization of knowledge.

KEYWORDS: University extension project, teaching, quilombola communities, photography.

\section{INTRODUÇÃO}

O presente artigo aborda os resultados preliminares do projeto de extensão "Revelando histórias do Seridó Negro". O projeto buscou, inicialmente, conhecer histórias das populações negras da região Seridó do Rio Grande do Norte, especificamente na comunidade da Boa Vista, município de Parelhas. A escolha da Boa Vista se deu pelo histórico de parcerias da comunidade com instituições como a UFRN e a abertura de sua Associação de Moradores á proposta do 
projeto de extensão do IFRN, campus Currais Novos. Através de metodologias da imagem e da voz que retratam a vida cotidiana, buscou dar visibilidade à cultura negra seridoense para materializa-la em fotografias.

A presença das populações negras, de descendência africana, é um fato histórico, social e cultural vivo na região Seridó do estado do Rio Grande do Norte. Esse fato é constatado pela tradição viva de seu povo expressa em sua cultura e reconhecido pela pesquisa historiográfica (CASCUDO, 1984) e antropológica (CAVIGNAC, 2007, 2014). Embora tenhamos vivido importantes conquistas nos últimos vinte e cinco anos, com a promulgação da Constituição Federal de 1988, a publicação da lei 10.639/2003 de Ensino da História e da Cultura Afro-brasileira nas redes de ensino e o Estatuto da Igualdade Racial, como também do Decreto n 4.887/2003, os indivíduos de pele negra e suas populações ainda são objetos de violência persistente que os coloca em situação de desvantagem em relação aos indivíduos melhor posicionados na estrutura social. Esse quadro de violência pode ser percebido quando analisamos o perfil da vitimização por homicídio no Brasil (WAISELFISZ, 2012), onde predomina a mortalidade violenta de homens jovens, negros e pobres. As conquistas, como também os retrocessos ao longo dos anos, configuram um ponto de chegada, o qual nos lembra que temos uma jornada pela frente na construção de processos de reconhecimento de demandas reprimidas e na construção políticas públicas para igualdade de oportunidades.

$\mathrm{Na}$ contemporaneidade, no contexto de uma Terceira Revolução Industrial, as tecnologias da informação e da comunicação têm se mostrado poderosas ferramentas na mediação dos processos sociais, ainda mais quando consideramos sua relação com o papel que as imagens têm desempenhado na formação de ideias, da consciência e da crítica. Esse papel, no entanto, é ambivalente sendo imprescindível entender o campo de possibilidades para o seu uso. Para Castells (2005), o informacionalismo, tal como o industrialismo de meados do século XVIII, é um modo de desenvolvimento surgido com a reestruturação do modo de produção capitalista no final do século XX. Para ele, a informacionalização da sociedade se deu a partir da revolução tecnológica que se constituiu como paradigma na década de 1970. Para Castells a tecnologia:

É uma força que provavelmente está, e mais do que nunca, sob o atual paradigma tecnológico que penetra no âmago da vida e da mente. Mas seu verdadeiro uso na esfera da ação social consciente e a complexa matriz de interação entre as forças tecnológicas liberadas por nossa espécie em si são questões mais de investigação que destino (CASTELLS, 2005, p. 113).

Algumas características elencadas por Castells descrevem bem a natureza do paradigma da revolução da tecnologia da informação: 1) a informação é tecnologia para agir sobre a 
informação e não apenas informação para agir sobre a tecnologia como o foi nas revoluções tecnológicas anteriores; 2) os processos sociais são diretamente moldados pelo novo meio tecnológico, ou seja, há uma penetrabilidade dos efeitos das novas tecnologias; 3) a lógica de redes, com a qual as tecnologias da informação podem estruturar-se ou adaptar-se em função da crescente complexidade de interação e configuração de processos que preservam a flexibilidade do "não-estruturado" (força motriz da inovação na atividade humana); 4) a flexibilidade é outro aspecto que distingue o paradigma da tecnologia da informação. Sua capacidade de reconfiguração é um aspecto decisivo em uma sociedade caracterizada pela constante mudança e fluidez organizacional; 5) a variedade das tecnologias em informação e comunicação converge para um sistema altamente integrado, a convergência entre diferentes campos tecnológicos resulta de uma lógica compartilhada na geração da informação.

Este desenvolvimento caracterizado pelas tecnologias de informação e comunicação é a base da globalização econômica. Na perspectiva de Castells, a globalização

É um processo segundo o qual as atividades decisivas num âmbito de ação determinado (...) funcionam como uma unidade em tempo real no conjunto do planeta. Trata-se de um processo historicamente novo (...) porque somente na última década se constituiu um sistema tecnológico (...) que torna possível essa globalização (CASTELLS, 1999, p. 149).

Para o autor o efeito mais importante e mais amplamente reconhecido da globalização, especificamente sobre a capacidade de intervenção do Estado nacional, é a globalização do capital e a interdependência dos mercados financeiros; o sistema estruturado em rede que "conecta o que vale e desconecta o que não vale" lembrando que a globalização é, ao mesmo tempo, segmentação e diferenciação, "e é precisamente o desenvolvimento de novas tecnologias de informação e comunicação o que permite uma articulação cotidiana de uma rede de instituições e organizações cuja complexidade a faria não-manejável se não fosse capaz de interatividade informática" (CASTELLS, 1999, p. 164).

É possível compreender, portanto, que a informacionalização da contemporaneidade não se trata de um objeto fora da realidade social mas, enraizada nesta, está marcada por conflitos e tensões, e por esta razão abre-se um campo de possibilidades para atores sociais concretos. A compreensão desta realidade implica numa formação humanística em todos os níveis de educação capaz de fazer o indivíduo exercitar sua reflexividade continuamente. No caso da formação de nível médio na forma integrada à formação técnica, ressaltamos, a relevância da formação humanística, especificamente das disciplinas de Sociologia (que traz em seu escopo saberes da Antropologia Social e da Ciência Política) e Sociologia do Trabalho como matérias estratégicas na formação intelectual para vida prática. Nesse sentido o estudante é estimulado 
a entender a relação entre parte e todo, entre local e global, situação e contexto, movimentos com os quais se depararão em suas trajetórias acadêmica e profissional.

Entendemos a importância estrutural de todo o currículo para o estudante, no entanto, apontamos para a sociologia, não apenas porque essa é uma experiência desenvolvida a partir da disciplina, mas pelo fato de que a mesma traz em seu escopo temas, autores e discussões que buscam desenvolver a criatividade, a cooperação e o manejo de saberes relativos a estruturas e sistemas. Nessa dinâmica aplica-se a discussão das ciências humanas e das tecnologias da informação, como forma de compreender a diversidade cultural (global e local), e do manejo prático de equipamentos para conjugação desses saberes.

\section{EMBASAMENTOS TEÓRICOS E METODOLÓGICOS}

A história das populações negras do Rio Grande do Norte, assim como do Brasil, é de negação e violência (FERNANDES, 2008). E o presente, mesmo após inúmeras conquistas, ainda é marcado pela discriminação racial, herança de um passado colonial e escravocrata. Curiosamente, quando nos debruçamos sobre os dados demográficos, a presença negra é marcante, sobretudo quando consideramos o censo demográfico de 2010 (BRASIL, 2010), quando mais da metade da população do estado se declarou negra ou parda. No entanto, o debate sobre raça e racismo, ou sobre preconceito racial, é acirrado e longe de ter um consenso final.

Problemas relativos às relações etnicorraciais não são exclusivas da formação da população brasileira, mas atravessam a história de todas as sociedades em diáspora. No caso do Brasil contemporâneo, lidamos com a manutenção de "fronteiras étnicas" que remontam ao seu passado colonial e reforçam continuamente situações de preconceito, de discriminação e de violência. Ao considerarmos a ideia de fronteira entre grupos étnicos, em termos teóricos, percebemos que as mesmas são, entre os grupos, mais ou menos estáveis; que elas não representam necessariamente barreiras; que a manutenção dessas fronteiras não depende da permanência da cultura (portanto, uma cultura parece mudar, mas as fronteiras entre os grupos permanecem); que as fronteiras são produzidas, reproduzidas e manipuladas pelos atores sociais em suas interações (POUTIGNAT, 2011). Esse último dado abre um campo de possibilidades, já que é na vida cotidiana que as desigualdades e as violências podem ser percebidas, abarcadas e superadas.

A manutenção dessas fronteiras, quando se trata do Brasil, coincide com um quadro de negação da cultura e das práticas das populações negras afrodescendentes, e nega, por conseguinte, conhecimentos, habilidades e tradições locais que são, não obstante, constitutivos do patrimônio cultural brasileiro. Essa negação se dá por uma construção histórica de preconceito de cor e racismo associados a práticas de dominação política e econômica (GUIMARÃES, 2008). A convivência, considerada erroneamente, "harmônica" e "democrática" entre grupos étnicos no 
Brasil nega, portanto, uma situação de subalternidade social e negação cultural.

Concordamos com Foucault quando o mesmo afirma que onde há dominação, existe ali a possibilidade de resistência, portanto, de como não ser governado daquela forma (FOUCAULT, 2004). Se pensamos, portanto, os quilombos durante a escravidão, ali encontramos o eco da resistência, desse cuidado de si que implica uma atitude crítica, em outras palavras, a luta contra um poder opressor. Para Munanga,

Pelo conteúdo, o quilombo brasileiro é, sem dúvida, uma cópia do quilombo africano reconstruído pelos escravizados para se opor a uma estrutura escravocrata, pela implantação de uma outra estrutura política na qual se encontraram todos os oprimidos. Escravizados, revoltados, organizaram-se para fugir das senzalas e das plantações e ocuparam partes de territórios brasileiros não-povoados, geralmente de acesso difícil. Imitando o modelo africano, eles transformaram esses territórios em espécie de campos de iniciação à resistência, campos esses abertos a todos os oprimidos da sociedade (negros, índios e brancos), prefigurando um modelo de democracia plurirracial que o Brasil ainda está a buscar (MUNANGA, 1996, p. 63).

Se mais adiante, consideramos a Frente Negra Brasileira entre os anos de 1930 e 1940 e o Movimento Negro Unificado nos anos 1980, nos depararemos com formas renovadas de resistência e luta. A Constituição de 1988 representará, portanto, um ponto alto nas conquistas do movimento e do ativismo negro junto à criação da Fundação Palmares e a consagração de Zumbi como herói nacional (GUIMARÃES, 2008).

Com o advento de uma sociedade em rede, como apontamos anteriormente, e do que também temos chamado de "cibercultura" e de indivíduos e grupos interconectados, há a ampliação de um campo de possibilidades para novos processos sociais e epistemológicos e, com isso, o desenvolvimento de habilidades, a preservação das tradições (como também a reinvenção destas) e o nascimento de um novo ativismo e mobilização política. Blogs, fóruns virtuais, canais de comunicação audiovisual e redes sociais, oferecem meios de produção e difusão de conhecimentos, habilidades e tradições que, por sua vez, constituem meios de formação da consciência e da identidade. Quanto a esta última dimensão, percebemos uma poderosa relação entre a produção de imagens (fotografia e vídeos curtos) e sua difusão, seja pelos meios "tradicionais" (catálogos, livros, exposições) seja pelos meios contemporâneos que tem a esfera virtual como plataforma (sites, blogs, redes sociais).

O uso da imagem e suas variantes, bem como da internet e seus meios, quando se trata de projetos e suas estratégias, têm sido utilizados tanto para fins acadêmicos quanto para fins sociais e técnicos. No que toca os fins acadêmicos, a dupla (imagem e internet) tem colocado importantes questões, como por exemplo, o que podemos chamar de uma textualidade das imagens 
(BARBOSA, 2006; BARBOSA JR., 2013), ou seja, nas ciências humanas e, mais especificamente nas ciências sociais, durante muito tempo as imagens foram meramente ilustrativas. Hoje, o uso das imagens, e sua constante reinvenção no espaço virtual tem ido além. No sentido de que elas também são textos e têm um código a ser decifrado, as imagens estabelecem um processo de comunicação, colocam uma mensagem entre emissor e receptor, mas também vão além. Em “O mundo-imagem", ao problematizar a emergência da imagem, notadamente através da fotografia, Susan Sontag coloca as questões da relação imagem e real, e a reprodutibilidade imagética. É o caso da câmera fotográfica e da fotografia em suas possibilidades de controle de registro da informação e da decifração do comportamento. Para a autora:

Ao ser fotografada, determinada coisa torna-se parte de um sistema de informações amoldado a esquemas de classificação e armazenamento que vão desde a sequência de instantâneos colados, em ordem, nos álbuns de família, até a acumulação pertinaz e o arquivamento meticuloso necessários para a utilização da fotografia nas previsões do tempo, na astronomia, na microbiologia, na geologia, nas atividades policiais, no treinamento e diagnóstico dos médicos, no reconhecimento militar e na história da arte. A fotografia faz mais do que redefinir o conteúdo da experiência cotidiana (pessoas, coisas, eventos, o que quer que vejamos - ainda que diferentemente e muitas vezes com desatenção - com a visão natural) e acrescenta vastas quantidades de material que jamais chegamos a ver (SONTAG, 1983, p. 150).

No que diz respeito aos procedimentos operacionais, fins acadêmicos e sociais podem coadunar-se quando, por exemplo, do uso da metodologia visual photovoice. 0 método e processo participativo consiste, basicamente, na elaboração de fotografias por seus participantes, discussão em torno de seus objetos (elementos da vida cotidiana) e exposição fotográfica. "VOICE" é um acrônimo que significa Voicing Our Individual and Collective Experience ("expressando a nossa experiência individual e coletiva") (WANG \& BURRIS, 1997, p. 381). Para Gerkhe, Barbosa Jr. e Milito, pesquisadores que utilizaram o método para processos de comunicação social e turismo no litoral do estado do Rio Grande Norte, Brasil, o método tem a seguinte gênese:

Ele foi desenvolvido a partir de três fontes: primeiro, a literatura teórica de educação para a autonomia, os estudos feministas e o documentário fotográfico. Em segundo lugar o esforço de fotógrafos e educadores participativos com o desafio da autoria documental e, em terceiro 
lugar, a experiência obtida por Wang e Burris (1994 e 1997) na pesquisa desenvolvida com mulheres camponesas de Yunnan, fronteira com Burma, Laos e Vietnam (GERKHE, BARBOSA JR., MILITO, 2015, p. 1006).

No que toca o público-alvo do projeto de extensão, que inspirou esse texto, a comunidade de Boa Vista no município de Parelhas/RN, importa destacar que a mesma é uma das três comunidades quilombolas certificadas pela Fundação Palmares. Para Cavignac,

Tradicionalmente, as festas, as danças e as devoções são realizadas para honrar os "santos negros", mas poucos fazem uma relação entre as festividades e o sistema colonial. Não existe uma explicação da presença histórica dos grupos na localidade, a escravização das populações de origem africana e a questão étnica são assuntos evitados - sobretudo em frente aos antigos donos! Assim, a designação "negro" é diretamente associada ao folclore, à dança e à festa (CAVIGNAC, 2014, p. 100-101).

A busca de registros orais e de informações históricas sobre as populações afro-brasileiras do Seridó permite apreender o discurso nativo e as percepções do mundo de um conjunto de indivíduos e grupos que têm em comum trajetórias históricas marcadas pela exclusão e pelo estigma (IDEM, p. 102).

Portanto, a experiência da pesquisadora na região Seridó, especificamente na Boa Vista, atesta a importância de projetos de pesquisa e extensão que tenham como objetivo o reconhecimento da cultura e a criação de meios para a sobrevivência das memórias, que não são simples reproduções dos fatos, mas a elaboração e re-elaboração das práticas sociais e de si.

Hoje, o lugar marginal imposto aos afro-brasileiros, seja na história, seja na paisagem social, começa a ser questionado pelos interessados que se assumem como quilombolas: ao saírem do esquecimento, os grupos descobrem direitos, caminhos, interlocutores e novas oportunidades, adotam modelos gerais de afirmação identitária que, gradativamente, serão reapropriados e reinterpretados em função das expectativas (IDEM, p. 110).

Dessa forma, a experiência antropológica de pesquisa e extensão junto à Boa Vista, deixounos uma proposta inquietante que foi a de oportunizar a elaboração de suas próprias histórias no presente. Através da voz e da imagem fotográfica e, ainda, das novas tecnologias da informação 
e da comunicação, abre-se um campo de possibilidades para a construção de novos processos epistemológicos "nativos" e de reconhecimento de demandas sociais reprimidas.

\section{RELATANDO A EXPERIÊNCIA}

Como já descrito, o presente texto trata das interseções entre ensino e formação humanística no contexto do projeto de extensão "Revelando histórias do Seridó negro", a partir de uma experiência prática com fotografia. A ideia para elaboração do projeto se deu a partir das discussões realizadas em sala de aula nas disciplinas de Sociologia (onde foram trazidos temas como sociedade e processos de socialização; cultura e ideologia; e, política e movimentos sociais) e Sociologia do Trabalho (onde são abordados o mundo do trabalho, a reestruturação produtiva do capital e a sociedade em transformação).

Ao trazer a discussão teórica para o mundo prático da vida cotidiana, precisamente ao contexto da região Seridó no estado do Rio Grande do Norte, veio à tona a questão histórica, demográfica, social e cultural de suas populações negras. São conhecidas na região as comunidades quilombolas da Boa Vista, município de Parelhas/RN; Negros do Riacho, município de Currais Novos/RN; e, Macambira, município de Lagoa Nova/RN. Desse universo, tivemos uma interlocução mais estreita com a comunidade da Boa Vista no município de Parelhas através de sua associação de moradores.

O desenvolvimento do projeto se deu a partir da construção de três metas: 1. A construção de laços de confiança; 2. A realização de oficina fotográfica no modelo Photovoice; e, 3. Apreciação do material fotográfico, resultado da oficina (a qual chamamos "Revelar histórias"). As ações dentro da primeira meta foram a realização de reuniões semanais com a equipe, discussão de bibliografia básica sobre a comunidade da Boa Vista e sobre fotografia, discussão das estratégias, interlocução com Maria do Socorro, líder da associação comunitária da Boa Vista, e a participação no evento "Roda de conversa: (in)visibilidades e resistências das comunidades quilombolas do RN", realizado pelo Núcleo de Arte e Cultura da UFRN no dia 29 de junho de 2017 no campus central da UFRN em Natal/RN.

Dentro da segunda meta, as primeiras ações foram constituídas por reuniões semanais com a equipe, a discussão de bibliografia básica sobre raça, etnia e fotografia, reunião de apresentação da proposta de oficina à comunidade da Boa Vista dos negros de Parelhas (que resultou numa sessão experimental de retratos dos participantes do encontro da associação), a execução da oficina, a feitura de 281 fotografias elaboradas pelos participantes e a equipe, como resultado da oficina. No que toca a terceira meta, esta se deteve na ação de apreciação, triagem e tratamento do material fotográfico resultante das experiências anteriores. Tratou-se de um passo fundamental para conclusão do projeto e para realização de uma exposição fotográfica futura. Tendo atendido em grande parte as metas e ações que propúnhamos, relatamos então nossas impressões gerais 
da experiência de execução do projeto.

Nossa primeira impressão diz respeito à receptividade da associação comunitária, e consequentemente da comunidade, à equipe e ao projeto. A nossa interlocução foi fluída, mas cabe colocar, conforme ouvimos durante a prospecção para montagem, bem como nos diálogos preparatórios para realização da oficina, que ao longo dos anos vem havendo um fechamento de algumas comunidades quilombolas a projetos sociais e de pesquisa e extensão. Tal fechamento se deve a atuação de indivíduos e entidades descompromissadas ou duvidosas que têm usado da imagem, da história e das experiências das comunidades para proveito próprio sem dar um retorno às comunidades.

$\mathrm{Na}$ Boa Vista encontramos um histórico de projetos de pesquisa e extensão, notadamente com a Universidade Federal do Rio Grande do Norte, que parece ter construído uma socialidade, em termos de abertura da comunidade e de uma consciência sobre os limites e possibilidades das parcerias. Ao nível do Poder Público, no entanto, a comunidade parece merecer um maior cuidado e políticas públicas que ajudem a população local a se manter na terra num quadro de estiagem e seca que vem se arrastando por anos. Esse quadro, muitas vezes desencoraja a juventude a se manter na comunidade ao buscar estudo e realização profissional fora.

Como já mencionado, a Boa Vista possui uma rica tradição marcada pela religiosidade na devoção à Nossa Senhora do Rosário, e pela sociabilidade na Dança do Espontão. A tradição se manifesta mais fortemente na festa anual dedicada à Nossa Senhora do Rosário durante o mês de novembro com novenas e festas. Essa realidade nos impeliu a pensar na possibilidade de registro da tradição via novas tecnologias pelos próprios boa-vistenses. A riqueza cultural da comunidade nos convenceu mais ainda sobre a importância de desenvolver ou potencializar habilidades fotográficas entre jovens da comunidade.

Outra impressão que tivemos foi o fato de que a realização da oficina de fotografia não se tratou, na ocasião, de apenas um "treinamento", já que a mesma, consistiu dentre outros procedimentos, na apresentação de técnicas básicas como luz e sombra, foco e enquadramento, e na apreciação de fotografias e fotógrafos. Percebemos que a oficina teve um amplo papel de lazer, ou seja, uma atividade lúdica diferencial que mostrou grande potencial de romper com a timidez e propiciar a descoberta de potenciais por parte dos participantes.

No que toca especificamente a oficina, esta consistiu inicialmente numa breve apresentação da história da fotografia, seguida por uma mostra ampla de fotógrafos como Marc Ferrez, Pierre Verger e Vivian Maier. Nesse primeiro momento, tratou-se de mostrar, no caso dos dois primeiros nomes, fotógrafos que num passado recente da história do Brasil e da fotografia retrataram as populações, especificamente os grupos étnicos. No caso de Pierre Verger, percebemos que as fotografias atraíram a atenção e os olhares dos participantes, justamente pela beleza com a qual Verger retrata as populações negras do Brasil e da África e suas culturas. A razão de trazermos a fotógrafa norte-americana Viviam Maier, deve-se a uma questão muito curiosa a respeito da mesma. Trata-se de uma babá estadunidense que não tinha formação em fotografia, que não chegou a expor seu material, portanto não fez fama, e foi descoberta após sua morte. Nesse sentido, 
a trajetória de Maier e suas fotografias, marcadas por uma sensibilidade antropológica, mostra como o desenvolvimento de uma visão aliada à uma câmera são capazes de captar momentos, emoções e concretiza-las em imagens.

Num momento seguinte, após dividir o grande grupo em pequenas equipes e dar-lhes instruções sobre os equipamentos, saímos ao entorno da associação para exercitar o que havia sido teorizado anteriormente. Tratou-se de uma experiência prática com fotografia onde as habilidades estimuladas durante o momento anterior foram desenvolvidas. A experiência prática também trouxe à tona um indicador de sucesso da atividade que é o completo envolvimento dos participantes e a expressão da satisfação quando se percebe que a atividade também se torna lazer. Outros indicadores são a abertura dos participantes ao aprendizado, a utilização de seus próprios modos de fazer ou o uso ativo da criatividade; e, ainda, a cooperação dos participantes entre si.

Como resultado dessa experiência obtivemos um total de 365 fotografias que foram submetidas posteriormente à triagem, tratamento/edição e curadoria. Como resultado final desse processo obtivemos 32 fotografias a serem enquadradas para exposição. Desse último resultado classificamos as fotografias em quatro categorias: 1. Experiências; 2. Paisagens da Boa Vista; 3. Vida comunitária da Boa Vista I; e, 4. Vida comunitária da Boa Vista II.

$\mathrm{Na}$ primeira categoria encontra-se fotografias que reúnem momentos durante a experiência que denotam espontaneidade e envolvimento. A segunda categoria traz imagens da paisagem da Boa Vista que varia do árido, passando por uma pequena porção de água à vegetação e montanhas (destaque para uma pedreira, elemento marcante da paisagem da Boa Vista). Na terceira categoria encontramos a vida comunitária em seu aspecto cotidiano: a presença contrastante de motocicletas e carroças; pessoas e animais em suas relações e a sociabilidade. Na quarta categoria ainda temos a vida comunitária, no entanto, com maior foco nas pessoas em sua relação com o lugar, no lazer e no trabalho.

\section{CONSIDERAÇÕES FINAIS}

O presente artigo abordou até aqui os resultados preliminares de uma experiência prática com fotografia dentro do projeto de extensão "Revelando histórias do Seridó Negro" executado na comunidade da Boa Vista dos negros de Parelhas/RN, através do qual buscou abordar a cultura negra seridoense. A presença dessa comunidade quilombola é um indicativo da diversidade cultural na região. Projetos dessa natureza importam como uma via de mão dupla: ao mesmo tempo em que estreita laços entre sociedade e instituição de ensino, estendendo o saber prático à primeira, criando um campo de possibilidades para ambas; abrem espaço para formação prática do estudante que passa a conhecer a realidade social e a diversidade cultural de perto.

Ao compreender a sociedade como um conjunto de grupos e indivíduos em suas relações e 
interações, mediados pela cultura, por ideologia e por relações de poder, entende-se que esta não se trata de um fenômeno "harmônico", mas cujo equilíbrio envolve conflito e disputa (SIMMEL, 2009). Sendo capaz de orquestrar os saberes humanísticos da História, da Geografia, de Línguas, da Filosofia e da Sociologia, o estudante pode desenvolver uma sensibilidade diferencial para o mundo. Em se deparar com temas acadêmicos, mas não descolados do mundo real (em que pese as relações sociais, a cultura e a ciência/filosofia política), estimula-se a compreensão de situações locais em suas relações com contextos amplos. Como já mencionado, tais conteúdos habilitam o estudante a manejar saberes relativos a estruturas e sistemas.

Tendo entendido como a estrutura social brasileira, em seu processo de formação criou uma demanda reprimida de direitos, como é o caso das populações negras, entende-se que esse processo que as colocou em uma situação de negação e violência. Entende-se com isso, ainda, a necessidade de se criar condições de resiliência para um melhor equilíbrio social, ou seja, para mais igualdade de oportunidades e afirmação da estima e da cultura. No contexto de um projeto como o que foi realizado apresenta-se limites e possibilidades. Os limites dizem respeito ao fato de que um projeto de curta duração e com poucos recursos não é capaz de agir sozinho sobre as principais necessidades de uma comunidade quilombola ou de qualquer outra comunidade. As possibilidades tratam-se da aproximação instituição e sociedade através de uma experiência prática com fotografia que, ao desenvolver habilidades no manejo da imagem e motivar o registro da vida cotidiana e, portanto, da cultura, vai além em também criar condições de lazer e de desenvolvimento de um capital cultural.

No contexto de uma intrínseca informacionalização da vida social em suas ambivalências, ou seja, em "conectar" e "desconectar", num contexto de acirramento do uso das imagens para publicidade e propaganda, como também de ideologias de privatismo e do radical individualismo, é colocado o desafio para profissionais da educação e seus estudantes: como transformar a realidade social a partir do diálogo e da crítica desses saberes? Encontramos possibilidades, portanto, na interseção entre o ensino, a formação humanística e na experiência prática dos projetos de extensão para transformação dessa realidade.

\section{REFERÊNCIAS}

BARBOSA, Andrea. Antropologia e Imagem. Rio de Janeiro: Jorge Zahar Ed., 2006.

BARBOSA, JR. J. D. "Favela não é o lugar, são as pessoas". Desconstruindo a relação entre lugar e violência no Sarney e no Japão, Natal/RN. 2013. [Dissertação]

BRASIL. IBGE. Censo Demográfico, 2010. Disponível em: <www.ibge.gov.br>.

BRASIL. Lei 11.645/2008, de 10 de março de 2008 - Altera a Lei no 9.394, de 20 de dezembro de 1996, modificada pela Lei no 10.639, de 9 de janeiro de 2003, que estabelece as diretrizes e bases da educação 
nacional, para incluir no currículo oficial da rede de ensino a obrigatoriedade da temática "História e Cultura Afro-Brasileira e Indígena".

CASCUDO, Luís da Câmara. Viajando o Sertão. Natal/RN: Editora CERN, 1984.

CASTELLS, Manuel. Para o Estado-rede: Globalização econômica e instituições políticas na era da informação. In.: Estado e Sociedade em Transformação. São Paulo: Editora UNESP; Brasília: ENAP, 1999. p.148-171.

CASTELLS, Manuel. A Sociedade em Rede (Tomo I). São Paulo: Paz e Terra. 2005.

CAVIGNAC, Julie; MACEDO, Muirakytan K. Troncos, ramos e raízes! História e patrimônio cultural do Seridó negro. Brasília/DF: ABA; Natal/RN: Flor do Sal; EDUFRN, 2014.

CAVIGNAC, Julie. Os filhos de Tereza: narrativas e religiosidades na Boa Vista dos Negros/RN. In: Revista TOMO. N 11. São Cristovão/SE, 2007

FERNANDES, Florestan. A Integração do Negro na Sociedade de Classes - Vol. I. Rio de Janeiro: Ed. Globo, 2008.

FOUCAULT, M. A ética do cuidado de si como prática da liberdade. In: Ditos \& Escritos V - Ética, Sexualidade, Política. Rio de Janeiro: Forense Universitária, 2004.

GERKHE, B. M; BARBOSA JR. J. D; MILITO, M. C. Photovoice e identificação de recursos turísticos endógenos no litoral do Rio Grande do Norte-Brasil. In: Revista Pasos. Vol. 13. Nㅜ 5. P. 1003-1017, 2015.

GUIMARÃES, Antônio Sérgio A. Preconceito racial: modos, temas e tempos. São Paulo: Ed. Cortez, 2008.

MUNANGA, Kabengele. Origem histórica do quilombo na Àfrica. Revista USP, São Paulo, n. 28, p. 56-63, dez-fev, 1995/1996.

POUTIGNAT, Philippe. Teorias da etnicidade: seguido de grupos étnicos e suas fronteiras de Frederik Barth. São Paulo: Ed. Unesp, 2011.

SIMMEL, Georg. "Conflict". In: Sociology: enquiries into the construction of social forms. Koninklijke Brill NV, Leiden, The Netherlands, 2009.

SONTAG, Susan. O mundo-imagem. In: Sobre a fotografia. Rio de Janeiro: Editora Arbor Ltda., 1983.

WAISELFISZ, Julio Jacobo. Mapa da Violência 2012: A Cor dos Homicídios no Brasil. Rio de Janeiro: CEBELA, FLACSO; Brasília: SEPPIR/PR, 2012.

WANG, C; BURRIS, M. A. 1997. Photovoice: Concept, Methodology, and use for Participatory Needs Assessment. In: Health Education and Behavior, Vol. 24 (3): 369-387. 